\title{
Infectious Bronchitis Disease in Poultry its Diagnosis, Prevention and Control Strategies
}

\author{
Samad A*, Abbas A, Mehtab U, Ur Rehman Ali \\ Khera $H$, Rehman $A$ and Hamza $M$ \\ Muhammad Nawaz Sharif University of Agriculture, \\ Multan, Pakistan \\ *Corresponding author: Abdul Samad, Muhammad \\ Nawaz Sharif University of Agriculture, Multan, Pakistan
}

Received: September 17, 2021; Accepted: October 13, 2021; Published: October 20, 2021

\begin{abstract}
Avian Infectious bronchitis (IB) is profoundly one of the main diseases associated with respiratory syndrome in domestic poultry causing significant economic losses to poultry production. Avian Infectious Bronchitis (IB) has a place with Coronaviridae family, which causes respiratory illness, diminished creation of flying creatures, nephrotic Syndrome, and unsalvageable harm to oviduct, which can cause the crenation of anomalous eggs. Inoculation programs currently are pointless because of the outrageous hereditary varieties of IBV. Consequently, an exact and fast serotype assurance is a significant factor in controlling IBV. Compelling analytic instruments are likewise expected to analyze IB diseases in the field and to distinguish diverse serotypes and variations. Ideal administration for forestalling IB in flying creatures incorporates ideal inoculation with live or inactivated Vaccines containing flowing strains and severe disconnection of the contaminated fowls. Great administration and sterile practices in poultry units can handle the spread of IB among groups by and large. The idea of DNA vaccination with spike protein quality has altered the idea of IB immune prophylaxis as it has been found to evoke an adequate invulnerable reaction. Atomic science-based identification and control procedures must be created alongside the up degree of customary strategies to handle the developing danger presented by this microorganism the sickness can be adequately controlled in the years.
\end{abstract}

Keywords: Avian Corona Virus; Poultry; Pathology; Prevention

\section{Introduction}

Infectious bronchitis virus is classified currently as avian coronavirus, which belongs to genus Gamma-coronavirus, family Coronaviridae $[1,2]$. It is a well-known and widely spread disease, which causes large economic losses to the poultry industry by showing respiratory and reproductive signs, decreased productive performances, and increased mortality, particularly when nephron pathogenic strains or secondary infection is involved [3]. IBV is an enveloped virus with a one stranded positive-sense RNA genome of approximatively $27 \mathrm{~kb}$, which shows the following gene organization: 5'UTR-1a/1ab-S-3b-3ba-E-M-5b-5a-N-3'UTR [4].

Infectious bronchitis is a disease of economic importance affecting all the major poultry sectors. It was first originated in the United States affecting young chickens in $1931[5,6]$. Strains of the IBV virus cause mutation, which becomes more lethal [7] while others remain limited to an area with no inclination for extension. In countries where intensive livestock is followed, the infection rate can reach up to $100 \%$ [8].

To stop the spread of IBV can be handle via live and inactive vaccines. Both types of vaccines have their drawbacks. The inactive vaccines can only activate the humoral immune response while no cellular response is activated, it also enhances the activity of cytotoxic $\mathrm{T}$ lymphocytes $[9,10]$. Live vaccines can easily modulate the gene, which affects the spicules and in return reduces.

After engaging in several replication cycles, the virus is genetically modified to "Quasispecies", specifically on their Subunit which is S1
[11]. Live vaccines can maximize the rate of mutation up to $1.5 \%$ [12]. Failure of vaccine can cause the appearance of the mutation [13]. The establishing of new vaccine strategies is important for better control of the disease [14]. Recent researches indicated that recombinant vaccines are better than other conventional vaccines. Different bacterial and viral agents can be modified genetically to act as vectors that show different genes encoding the major structural viral proteins. Protective immunity is developed when we use recombinant vaccines The substitute and appropriate choice is based on complete knowledge of the process of infection and protective immune response's nature which help to choice of protecting antigen [15].

The main of this study is to ornate the molecular characteristic of chicken IBV, to elaborate the cellular immune and Humoral responses, specifically those played by cytotoxic $\mathrm{T}$ lymphocytes in the handling of this infection and the role played by spike (S) nucleoprotein $(\mathrm{N})$ and Glycoprotein(S)in the induction of immune response. Genetic therapy and other Biotechnological advance in IB control have been assessed by many recent researchers.

\section{Diagnosis}

Diagnoses of IB can be done by the clinical expression of diseasecausing antibodies titers, antigen indication, and acclaimed DNA in the clinical material and sections of tissue IBV can be gain from a respiratory organ-like pulmonic, kidney \& windpipe of sick bird [1618]. The site of antigen detection is the liver and pancreas. Spleen and windpipe are for examination or microscopic examination of tissue [19]. 
Separation of the primary virus requires two to three blind passages. Which may be a difficult and time taking process that's why the embryo of hen is free with Particular microbes and their organ cultures of Trachea (OCT) are recommended for separation of IBV [20]. Other indication methods like Immune histochemistry [21,22] or in situ assimilation [23] can be used. We use a microscope to detect protein $(\mathrm{N})$ from fit and unaffected cells, it tells us the existence of viral proteins $(\mathrm{N})$ which is very important for replication in the host [24] Further we can detect IB by different other tests like Virus Neutralization test Hemagglutination Inhibition, etc.

\section{Prevention and Control Strategies \\ Immunological control (Vaccination)}

In many countries, one-day-old chicks are pass through the vaccination process to boost immunity against IBV. Mostly the chicks are being vaccinated through the water, as it is the easiest way of vaccination. We should use a vaccine of lower virulence as a higher level of virulence causes respiratory reactions as the Immunity of the chick is too low that it can protect the respiratory Tract only [25]. There are three types of Vaccines Live Vaccines, inactivated and killed vaccines. Live vaccines are usually or the broiler Breeder and layer's initial Vaccines. A vaccine is usually injected when layer or Breeder is near to period of laying eggs [26]. Vaccination help to boost immunity for a long time this would provide long life immunity.

\section{Live vaccine}

Massachusetts strain $\mathrm{H} 120$ is the common example of a live vaccine and it is a mild vaccine. It is an important vaccine at the start of the flock, which produces long-term immunity without having any bad impact on bird's immune system regions. Initially, the Immunization would be done via the ocular, intramuscular route, or tracheal route. That method is economical; increases regional and also whole systematic immune response. But suddenly vaccines may show reactions after few days of vaccination $[27,28]$. Ma5, a single segment immunization, is not severe, a single segment can be added in the first program of immunization with IB 4/91 vaccines and inactivated immunization provide immunity from many Infectious Bronchitis Virus variants. Live immunization is normally practiced on layers and breeders at a young age to keep regional protection of respiration tract and is recommended in the location of ultra-level of field challenges. However, vaccine strain should select on the basis of strains prevalent in countries. Protection against analogous, reference strains and serotype fields could be provided by the vaccine [29].

By a combination of Mass, JMK (A strain), Conn, or Mass Ultra levels of Protection against some strains (heterologous) develop. The occurrence of different variants of the virus has very complex and increased disease prevention costs and recommended to use of regional strains in vaccines for the efficient protection against disease. The function of inactivated immunization is to avoid depression, decrease in number of egg and meat production. The Massachusetts (Mass or M41) strain is the most well-known because it represents initial isolates from many areas [30-33].

\section{Inactivated vaccine (Inactive immunization)}

Inactivated immunization diminishing enduring insusceptibility, show no immunization responses, normally expensive than live antibodies and a mix of numerous antigens separated from Infectious
Bronchitis Virus can be accomplished when given independently. Raised degrees of flowing antibodies were animated by inactivate immunizations after that live immunizations, along these lines it is helpful in a reproducer program where maternal neutralizer insurance is required in any case, because of enlistment of better $\mathrm{T}$ cell reactions and delivering a higher neighborhood counteracting agent (IgA) incitement, changed live antibodies assume a critical job in ensuring business fowls (layers). Chickens should be appropriately live immunized, to use the capability of the inactivated vaccine so in 4-6 weeks greater concentration of antibodies would be obtained [34]. Further, inoculation projects might be streamlined by consolidating inactivated antigens against at least two serotypes (or at least two sicknesses) into one immunization (vaccine) [35].

\section{Environmental control}

The control is highly dependent upon good management practices by proper bird density in the farm, quality of air, following strictly biosecurity measures, etc [36]. However, even favorably handled IBV-positive flocks were estimated to yield $3 \%$ less than free Flock of IBV $[37,38]$. The first barrier of IBV is to follow strictly Biosecurity measures $[39,40]$. Disinfection of the farm is one of the major tools in minimizing the risk associated with the IBV virus. There is a risk of viral disease in the shed; even, However, biosecurity alone rare chance of complete prevention from disease transmission.

Vaccination of the flock should be done according to the vaccination protocol, still, it cannot fully assure the prevention but decrease in the incidence of disease in the flock. For instance, H120vaccinated animals showed a minimize viral transmission $(\mathrm{R} 0<1)$ and shedding after homologous challenge in the condition of experiments [41].

\section{Future Perspectives}

With the advance of Microbiology In different laboratories Novel vaccine-like Subunit, Vector, and DNA vaccine using glycoprotein (S1) gene along with reserve genetic vaccine have tried [42]. The utilization of DNA (S protein-based DNA) antibodies changes idea of inoculation as oppose to Infectious Bronchitis [18]. Alikecustomized antibodies would be intended to suit the locally overall Infectious Bronchitis Virus strains and the issue of weakened live strains returning to harmfulness can stay away. The vector-based or recombinant antibodies are additionally intended to present antigens from at least two infections which go about as multivalent immunization providing assurance against at least couple of illnesses. DNA immunization is another promising zone because appeared in starting clinical preliminaries. Such new-age immunizations could be managed securely in egg or to chickens. The adequacy of such immunizations could be tried in huge scope tests prior to present in order a business reason $[43,44]$. This required great importance to battle this monetarily significant and arising poultry microorganism by adjusting and creating more current diagnoses, compelling and more secure antibodies, investigating novel therapeutics, and given fitting avoidance and handling procedures

\section{Conclusion}

This review shows that how can we detect Infectious Bronchitis Virus and also tells that how can we fix it moreover this review summarizes the modern Knowledge of IBV. The results of modern 
vaccinology genetic researches are very motivating and promising. Fact is that fact, the control of IBV has recorded a great evolution with recombinant vaccines.

\section{Acknowledgement}

All authors acknowledge the efforts done by Abdul Samad undergraduate students of Poultry Sciences at Department of Veterinary and Animal Sciences at MNS Agriculture of Multan.

\section{References}

1. Ismael I Hasan, T Saad Rasheed, A Nawar Jasim, Shakor MK. Pathological effect of infectious bronchitis disease virus on broiler chicken trachea and kidney tissue. Vet World. 2020.

2. Woo PCY, Skp Lau, Csf Lam, Ccy Lau, Akl Tsang Lau JHN, et al. Discovery of seven novel mammalian and avian coronaviruses in the genus Delta coronavirus supports Bat coronaviruses as the gene source of Alpha coronavirus and Beta coronavirus and avian coronaviruses as the gene source of Gamma coronavirus and Delta coronavirus. J Virol. 2012; 86: 39954008.

3. Franzo G, Legnardi M, Tucciarone CM. Evolution of infectious bronchitis virus in the field after homologous vaccination introduction. Vet Res. 2019: 50-92.

4. Matteo Legnardi, Maria Claudia, Tucciarone, Franzo Giovanni, Cecchinato Mattia. Infectious Bronchitis Virus Evolution, Diagnosis and Control. Vet Sci. 2020; 7: 79.

5. Milek J, Domanska Blicharz K. Coronaviruses in Avian Species-Review with Focus on Epidemiology and Diagnosis in Wild Birds. J. Vet. Res. 2018; 62 249-255.

6. Butcher GD, Shapiro DP, Miles RD. Infectious bronchitis virus: Classical and variant strains. IFAS Extension University of Florida USA. 2002: 1-4.

7. Rafiei MM, Vasfi Marandi M, Bozorgmehri Fard MH, Ghadi S. Identification of different serotypes of infectious bronchitis viruses in allantoic fluid samples with single and multiplex RT-PCR. J Virol. 2010; 3: 24-29.

8. Barry J, Goudar MS, Nighot PK, Kshirsagar SG, Ladman BS. Emergence of a nephron pathogenic avian infectious bronchitis virus with a novel Genotype in India. J Clini Microbiol. 2005; 43: 916-918.

9. Cavanagh D. Coronavirus avian infectious bronchitis virus. Vet. Res. 2007 38: 281-297.

10. Shu Wei Wu, Li Lei, Wang Yan, Zheng guo Xiao. CTL-Derived Exosomes Enhance the Activation of CTLs Stimulated by Low-Affinity Peptides. 2019: 1274.

11. Liu S, Zhang X, Gong L, Yan B, Li C. Altered pathogenicity, immunogenicity, tissue tropism and 3'-7 kb region sequence of an avian infectious bronchitis Coronavirus strain after serial passage in embryos. Vaccine. 2009; 27: 46304640 .

12. Lee CW and Jackwood MW. Origin and evolution of Georgia 98 (GA98), a new serotype of avian infectious bronchitis virus. Virus Res. 2001; 80: 33-39.

13. Cavanagh D, Davis PJ, Cook JKA, Li D, Kant A, G Koch. Location of the amino acid differences in the S1 spike glycoprotein subunit of closely related serotypes of infectious bronchitis virus. Avian Pathol. 1992; 21: 33-43.

14. Yan F, Zhao Y, Hu Y, Qiu J and Lei W. Protection of chickens against infectious bronchitis virus with a multivalent DNA vaccine and boosting with an inactivated vaccine. Vet. Sci. 2003; 14: 53-60.

15. Nascimento IP, Leite LCC. Recombinant vaccines and the development of new Vaccine strategies. Braz. J. Med. Biol. Res. 2012; 45: 1102-1111.

16. Pradhan HK, Mohanty GC, Verma KC. Isolation and characterization of vira agents from the reproductive tract of young chicks. Indian J Poult Sci. 1982 17: 143.

17. Verma KC and Malik BS. Isolation of infectious Bronchitis virus of poultry in India. Indian Vet J. 1971; 48: 887-892

18. Sylvester SA, Kataria JM, Dhama K, Senthil kumar N, Bhardwaj N and Rahul
S. Detection of avian infectious bronchitis virus infected allantoic fluid using SI gene serotype specific RT-PCR. Indian J Comp Microbiol Immuno Infect Dis. 2003; 24: 39-42.

19. Fan WQ, Wang HN, Zhang Y, Guan T, ZB Wang. Comparative dynamic distribution of avian infectious Bronchitis virus M41, HI 20 and SAIBK strains by quantitative real-time RT-PCR in SPF chickens. Biosci. Biotechnol. Biochem. 2012; 76: 2255-2260.

20. Cook JK, Darbyshire JH, Peters RW. The use of chicken tracheal organ cultures for the isolation and assay of avian infectious bronchitis virus. Arch Virol. 1976; 50: 109-118.

21. Nakamura K, Cook JK, Otsuki K, Huggins MB, JA Frazier. Comparative study of respiratory lesions in two chicken lines of different susceptibility infected with infectious Bronchitis virus: Histology, ultrastructure and immunohistochemistry. Avian Pathol. 1991; 20: 241-257.

22. Chen BY, Hosi S, NunoyaT, Itakura C. Histopathology and immunohistochemistry of renal lesions due to infectious bronchitis virus in chicks. Avian Pathol. 1996; 25: 269-283.

23. Collison SEW, Li J, Sneed LW, Peters ML, Wang L. Detection of avian infectious bronchitis viral infection using in situ hybridization and recombinant. DNA Vet Microbiol. 1990; 24: 261-271.

24. Hiscox JA, Wurm T, Wilson L, Britton P, Cavanagh, Brooks G. The coronavirus infectious Bronchitis virus nucleoprotein localizes to the nucleolus. J Virol. 2001; 75: 506-512

25. Kataria JM, Madan MC, Sohini D, Dash BB, Dhama K. Diagnosis and immune prophylaxis of economically important poultry diseases: A review Indian J Anim Sci. 2005; 75: 555-567.

26. Jackwood MW, Hilt DA, Callison SA. Detection of infectious bronchitis virus by real-time reverse transcriptase-polymerase chain reaction and identification of a Quasispecies in the Baudette strain. Avian Dis. 2003; 47: 18-724.

27. Matthijs MG, van Eck JH, Landman WJ, Stegeman JA. Ability of Massachusetts-type infectious Bronchitis virus to increase colibacillosis susceptibility in commercial broilers: A comparison between vaccine and virulent field virus. Avian Pathol. 2003; 32: 473-481

28. Bijlenga G, Cook JKA, Gelb J, De Wit JJ. Development and use of the Hstrain of avian infectious Bronchitis virus from the Netherlands as a vaccine: A review Avian Pathol. 2004; 33: 550-557.

29. De Wit JJ, van de Sande H. Efficacy of combined vaccines at day of hatch against a D388 challenge in SPF and commercial chickens. Proceedings of the $6^{\text {th }}$ International Symposium on Corona and Pneumo viruses and Complicating Pathogens. 2009. Rauischholzhausen Germany: 177-182.

30. Gelb J, Wolff JB and Moran CA. Variant serotypes of infectious bronchitis virus isolated from commercial layer and broiler chickens. Avian Dis. 1991; 35: $82-87$.

31. Gelb J Jr, Rosenberger JK, Fries PA, Cloud SS, Odor EM, Dohms JE, Jaeger JS. Protection afforded infectious bronchitis virus- vaccinated sentine chickens raised in a commercial environment. Avian Dis. 1989; 33: 764-769.

32. Cook JKA, Orbell SJ, Woods MA, Huggins MB. Breadth of protection of the respiratory tract provided by different live-attenuated infectious bronchitis vaccines against challenge with infectious bronchitis viruses of heterologous serotypes. Avian Pathol. 1999; 28: 477-485.

33. Terregino C, Toffan A, Beato MS, De Nardi R, M Vascellari. Pathogenicity of a QX strain of infectious Bronchitis virus in specific pathogen free and commercial broiler chickens and evaluation of protection induced by a vaccination programmed based on the Ma5 and 4/91 serotypes. Avian Pathol. 2008; 37: 487-493.

34. Ladman BS, Pope CR, Ziegler AF, Swieczkowski T, Callahan CJ, Davison $S$, et al. Protection of chickens after live and inactivated virus vaccination against challenge with nephron pathogenic infectious bronchitis virus PA/ Wolgemuth/98. Avian Dis. 2002; 46: 938-944.

35. Hong SM, Kwon HJ, Kim IH, Mo ML Kim JH. Comparative genomics of Korean Infectious Bronchitis viruses (IBVs) and an animal model to evaluate pathogenicity of IBVs to the reproductive organs. Viruses. 2012; 4: 2670- 
2683.

36. Ignjatovic J, Sapats S. Avian infectious bronchitis virus. Rev. Sci. Tech. OIE. 2000; 19: 493-508

37. Van Ginkel FW, Padgett J, Martinez Romero G, Miller MS, Joiner KS, Gulley $\mathrm{SL}$. Age-dependent immune responses and immune protection after avian coronavirus vaccination. Vaccine. 2015; 33: 2655-2661

38. McMartin DA. Virus Infections of Vertebrates. Virus Infections of Birds. Volume 4. Elsevier Science Publishers; Amsterdam, The Netherlands. 1993: 249-275.

39. Racicot M, Vaillancourt JP. Biosecurity: Assessing and managing risks Proceedings of the $12 \mathrm{e}$ Journées de La RechercheAvicole et Palmipèdes à Foie Gras; Tours, France. 2017: 20-34.

40. Van Limbergen T, Dewulf J, Klinkenberg M, Ducatelle R, Gelaude P, Méndez $\mathrm{J}$, et al. Scoring biosecurity in European conventional broiler production. Poult. Sci. 2018; 97: 74-83.
41. De Wit JJ, MCM de Jong, Pijpers A, Verheijden JHM. Transmission of infectious bronchitis virus within vaccinated and unvaccinated groups of chickens. Avian Pathol. 1998; 27: 464-471.

42. Dhama K, Mahendran M. Technologies and advances in diagnosis and control of poultry diseases: Safeguarding poultry health and productivity. Poult Technol. 2008; 2: 13-16.

43. Boots AM, Benaissa Trouw BJ, Hesselink W, Rijke E, Schrier C, Hensen EJ. Induction of anti-viral immune responses by immunization with recombinantDNA encoded avian coronavirus nucleocapsid protein. Vaccine. 1992; 10: 119-124.

44. Yu L, Z Wang, Jiang Y, Low S, Kwang JK. Molecular epidemiology of infectious bronchitis virus isolates from China and Southeast Asia. Avian Dis. 2001; 45: 201-209. 